Univerzitetska misao - časopis za nauku, kulturu i umjetnost [ISSN: 1451-3870]

Vol. 18, str. 76-87, 2019 god., web lokacija gde se nalazi rad:http://um.uninp.edu.rs

Tematska oblast u koju se svrstava rad: Društvene i humanističke nauke / podoblast: Sociologija Datum prijema rada: 19.07.2018.

Datum prihvatanja rada: 04.05.2019. doi: 10.5937/univmis1918076R

\title{
HYPOTHESIS OF THE SCIENTIFIC RESEARCH
}

Pregledni rad

\author{
Remzi Rexhep Bujari \\ Ministria e Punëve të Brendshme \\ r.bujari@hotmail.com \\ Bashkim Ali Azemi \\ Instituti Pedagogjik i Kosovës \\ alifazliazemi@gmail.com
}

\begin{abstract}
To clarify the hypotheses of scientific research and their role, it is first necessary to clarify the hypothesis concept.

The hypothesis is called the initial and unsafe assumption, but it is, however, unlikely to be verified, based on which the first explanations can be given about any occurrence, issue of relationships, problem, etc. They seek to find explanations, relationships, comparisons, predictions, generalizations, and theories. Assumptions should be formulated clearly and simply connected to your assumption for the expected results.

It represents the starting point for defining goals and tasks. Any experimental or explanatory work starts waiting for a certain result. This expectation is the result of a hypothesis. Hypothesis initiative and provides incentives for research and affects the search method.

Depending on the research hypothesis may be a theoretical or empirical puzzle. Research must have at least a hypothesis, which aims to provide answers. The researcher must determine which hypothesis is appropriate, develop new theories and concepts.

The hypothesis should traditionally be "proved" as a statement or expression of the relationship between two or more concepts. "It is a proven assertion of the relationship or relationship between two or more concepts, reasonable interpretations of what we find in our analysis of texts, content, people or events.

In the literature encountered different types of hypotheses, depending on the criteria to be taken to determine the type. We have the general hypothesis, auxiliary, null hypothesis, inductive, deductive, one-way, two-way, etc.

All the hypotheses of a study must not only be based on reasoning or intuition, but in the first place should be formulated and tested on the database collected through observation of realworld phenomena as occur, or through experiments. Testing the hypothesis can be done in several ways, but testing through advanced software is more accurate and more reliable.
\end{abstract}

Keywords: supposition, auxiliary, null, alternative, testing, hypothesis. 


\title{
HIPOTEZA E HULUMTIMIT SHKENCOR
}

\begin{abstract}
Për të sqaruar hipotezat e kërkimit shkencor dhe rolin e tyre, nevojitet fillimisht të sqarohet koncepti hipotezë.

Hipotezë quajmë supozimin fillestar dhe jo të sigurt, por që megjithatë ka gjasa të vërtetohet, në bazë të së cilës mund të jepen shpjegimet e para lidhur me ndonjë dukuri, çështje marrëdhënieve, problem etj.

Ato kërkojnë të zbulojnë shpjegime, marrëdhënie, krahasime, parashikime, përgjithësime dhe teori. Çdo punë eksperimentale ose shpjeguese nis duke pritur ndonjë rezultat të caktuar. Kjo pritje e ndonjë rezultati është HIPOTEZA. Hipoteza siguron nismë dhe nxitje për kërkim shkencor dhe ndikon në metodën e kërkimit.

Varësisht nga hulumtimi hipoteza mund të jetë një enigmë teorike ose empirike. Hulumtimi duhet të ketë, së paku, një hipotezë, së cilës synon t'i japë përgjigje. Hulumtuesi duhet të përcaktojë se cila hipotezë është e përshtatshme, të zhvillojë teori dhe koncepte të reja.

Hipoteza tradicionalisht duhet të 'provohet'si një pohim ose shprehje e marrëdhënieve midis dy ose më shumë koncepteve." Ajo është një pohim i testueshëm për marrëdhënien ose marrëdhëniet midis dy ose më tepër koncepteve,interpretime të arsyeshme të asaj që gjejmë në analizën tonë të teksteve, përmbajtjeve, njerëzve apo ngjarjeve.

Në literaturë hasen lloje të ndryshme të hipotezave, në varësi prej kriterit që merret për përcaktimin e llojit. Kemi hipotezën e përgjithshme, ndihmëse, hipotezën nul, induktive, deduktive, njëdrejtimëshe, dydrejtimëshe, etj.

Hipotezat duhet të jenë të formuluara qartë dhe thjesht, lidhur me supozimin tuaj për rezultatet e pritshme. Ajo përfaqëson bazën nismëtare për përcaktimin e qëllimeve dhe detyrave.

Të gjitha hipotezat e një studimi nuk duhet të bazohen vetëm në arsyetime ose në intuitë, por në radhë të parë duhet të formulohen dhe testohen mbi bazën e të dhënave që grumbullohen përmes vëzhgimit të dukurive të botës reale ashtu siç ndodhin, ose përmes eksperimenteve. Testimi i hipotezës mund të bëhet në disa mënyra, mirëpo testimi përmes programeve të avancuara është më i saktë dhe më i besueshëm.
\end{abstract}

Fjalë kyçe: supozim, ndihmëse, nul, alternative, testim, hipotezë

\section{HYRJE}

Para fillimit të një hulumtimi shkencorë-empirik, hulumtuesi/t, duhet të parashtrojnë hipotezat e hulumtimit. Hipotezat e hulumtimit është e vërtet se janë supozime paraprake, lidhur me rezultatet e hulumtimit, mirëpo nuk do të thotë se hipotezat nuk duhet të kenë kurrfarë baze shkencore. Hulumtuesi, derisa të vijë te ngritja apo parashtrimi i hipotezave shkencore, ka një rrugë të gjatë. Ai paraprakisht duhet të ketë njohuri mjaft të mira për dukurinë që do ta studiojë, të shfletojë literaturë relevante dhe pas një pune të mirëfilltë shkencore të parashtrojë hipotezat e hulumtimit, e jo të parashtrojë hipoteza nga hamendësimi i tij.

Hulumtuesi mund të parashtrojë një apo më shumë hipoteza, mirëpo duhet të ketë të qartë se, parashtrimi i hipotezave kërkon edhe testimin e tyre. Pas përfundimit të hulumtimit në terren, gjatë analizimit të të dhënave, kërkohet që të testohen hipotezat e hulumtimit dhe në bazë të kësaj mund të konstatojmë nëse janë mbështetur ose jo hipotezat e parashtruara para fillimit të hulumtimit. Mosmbështetja e 
hipotezave nuk do të thotë se hulumtimi ka dështuar, por tregon se supozimi i hulumtuesit nuk është mbështetur.

\section{HIPOTEZAT NË HULUMTIMET SHKENCORE}

Kur në shkencë shfaqet një problem, kërkohet një zgjidhje e tij.

"Hipotezat janë një lloj i veçantë i pyetjeve të hulumtimit... një pohim ose shprehje e marrëdhënieve midis dy ose më shumë koncepteve". (Matthews dhe Ross, 2010).

Ato janë pohim i testuar për marrëdhënien ose marrëdhëniet midis dy ose më tepër shkaqeve .

- Hipotezat burojnë nga supozimet ose nga frymëzimet, por pasi të jenë formuluar ato duhet të testohen në mënyrë të rreptë, duke përdorë metodën e duhur.

- Nëse parashikimet e nxjerra nga hipoteza juaj nuk dalin të jenë të sakta, atëherë ju duhet të braktisni ose të modifikoni hipotezën. Nëse parashikimet dalin të sakta, atëherë hipoteza juaj është provuar/supported dhe mund të qëndrojë përderisa teste të ardhshme të provojnë josaktësinë e saj.

- Hulumtuesi gjithnjë duhet të formulojë një hipotezë para se ta testojë atë.

- Me fjalë të tjera, të testojë hipotezat, ose do të zbulojë mënyrën më të mirë të zgjidhjes së një problemi kompleks.

Hipoteza propozohet si zgjidhje e supozuar e problemit të shtruar në formën e pyetjes kërkimore. (Kocani, 2008) Hipoteza është një ide ose sugjerim që bazohet në fakte të njohura dhe që përdoret si bazë për investigim të mëtejshëm. Ajo bazohet në gjetjet e kërkimeve të mëparshme, në literaturën për atë fushë, në eksperiencën e mëparshme të punës me atë subjekt.

Hipotezë quajmë supozimin fillestar dhe jo të sigurt, por që megjithatë ka gjasa të vërtetohet, në bazë të së cilës mund të jepen shpjegimet e para lidhur me ndonjë dukuri, çështje marrëdhënieve, problem etj.

Hipotezë, pra, s'mund të quhet çdo supozim, andaj kur e shkruajmë një hipotezë paraprakisht duhet të dimë se ajo duhet të ketë: logjik;

- Një mbështetje solide në faktet e konstatuara dhe në parimet e mendimit

- Të ketë relevancë, të jetë e thjeshtë;

- Zakonisht është një supozim që mund të verifikohet, ose do të verifikohet pas kërkimit.

Çdo hipotezë i ka tri tipare kryesore:

- Është e pasigurt, por mund të verifikohet;

- Është e përkohshme, ngase duhet të verifikohet ose të përgënjeshtrohet;

- Duhet të jetë patjetër e verifikueshme.

Përfundimisht një hipotezë origjinale është kur Kërkimet e deritanishme nuk kanë dhënë përgjigje për pyetjen, dhe ajo është një pyetje që kërkon përgjigje,dhe që ka hulumtues të interesuar për përgjigjen. 


\section{Llojet e hipotezave shkencore}

Koncepti i hipotezës, respektivisht i pohimit shpjegues të problemit, duhet kuptuar si proces në proces dhe jo si proces i cili një herë ndërmerret dhe përfundon. (Osmani, 2014)

Në literaturë hasen klasifikime të ndryshme lidhur me hipotezat.

Ndër llojet e hipotezave, janë edhe:

Hipoteza alternative Ha, e cila pohon ndikimet, dallimet, etj;

Hipoteza nul-zero Ho, e cila është në kundërshtim me hipotezën alternative dhe kryesisht e mohon lidhjen, ndikimin.

a. Sipas fazës së zhvillimit, hipotezat mund të ndahen në:

$>$ Hipoteza fillestare;

$>$ Hipoteza preliminare;

$>$ Hipoteza konkrete ose specifike.(Osmani, 2014)

b. Nga mënyra sesi nxirren hipotezat ndahen në:

$>$ Hipoteza induktive.- Mënyrë arsyetimi e kërkuesit për hipotezën që niset nga e veçanta dhe e pjesshmja për të nxjerr përfundime të përgjithshme;

$>$ Deduktive, mënyrë arsyetimi e kërkuesit për hipotezën që niset nga e përgjithshmja për të nxjerr një koncept të ri, më pak të përgjithshëm.

c. Në bazë të karakterit të raportit mes fakteve ekzistuese dhe të pritura, hipotezat mund të ndahen në:

$>$ Hipoteza deskriptive;

$>$ Hipoteza analitike.

d. Nga mënyra e formulimit të tyre, kemi:

$>$ Hipoteza alternative (e kërkimit): hipoteza që përshkruan parashikimin tuaj specifik për marrëdhënien në mes të variablave. (Hipoteza që studiuesi përpiqet të tregojë se është e vërtetë) (Simboli: H1 ose HA ).(Azemi\&Bujari, 2013)

Shembull i hipotezës alternative: Konfliktet në mes të prindërve, janë një faktor i cili mund t’i nxisë fëmijët të bëhen delikuentë.

Në kuadër të hipotezave të kërkimit hyjnë:

- Hipoteza njëdrejtimëshe.- Ky lloj i hipotezës shpreh një drejtim specifik në marrëdhëniet mes variablave dhe hipoteza nul shpreh se nuk do të ketë ndonjë ndryshim ose shpreh ndonjë parashikim por në drejtimin e kundërt me atë të hipotezës alternative.

Shembull i hipotezës njëdrejtimëshe:

Problemi: Ndikimi i konflikteve në mes të prindërve, të moshës shkollore, në sjelljet delikuente të tyre.

Hipoteza alternative (H1 ose HA): Konfliktet në mes të prindërve, janë një faktor i cili mund t'i nxisë fëmijët e moshës shkollore të bëhen delikuentë. 
Hipoteza nul (H0): Konfliktet në mes të prindërve, nuk i nxisin fare fëmijët e moshës shkollore të bëhen delikuentë.

- Hipoteza dydrejtimëshe. - Kur studiuesi beson se do të ketë një ndikimi, mirëpo hipoteza alternative nuk specifikon një drejtim në marrëdhënien mes variablave. Shembull i hipotezës dydrejtimëshe:

Problemi: Ndikimi i emisioneve televizive tek fëmijët e moshës shkollore në edukimin moral të tyre.

Hipoteza alternative (H1 ose HA): emisionet televizive ndikojnë në edukimin moral të fëmijëve të moshës shkollore.

Hipoteza nul (H0): Emisionet televizive nuk ndikojnë në edukimin moral të fëmijëve të moshës shkollore.

> Hipoteza zero (statistikore): hipoteza që përshkruan të gjitha rezultatet e tjera të mundshme në lidhje me marrëdhënien mes variablave në studim. (Hipoteza e kundërt e hipotezës alternative (Simboli: HO ose H0).

\subsection{NDËRTIMI I HIPOTEZAVE TË KËRKIMIT}

Hipotezat nxirren nga teoritë ekzistuese, sfidojnë ato, ose përpiqen të nxjerrin teori të reja.

Hipoteza duhet të përfundoj me një tezë e cila duhet të jap përgjigje për pyetjen, e cila deri më tani nuk ka dhënë përgjigje ose ka dhënë përgjigje por ne nuk jemi të kënaqur ose dëshirojmë ta verifikojmë ose fare nuk pajtohemi, duhet të jetë specifike pra nuk duhet të jetë e përgjithshme. Hipoteza duhet të të çojë tek përgjigjja ndërmjet shkakut dhe pasojës, në formë të një marrëdhënie logjike ndërmjet ndryshoreve me anë të një metode të zgjedhur (p.sh. krahasuese, etj.)

Hipoteza është një parashikim specifik dhe i testueshëm empirikisht për një marrëdhënie midis dy ose më shumë variablave. Ajo përshkruan në mënyrë konkrete se çfarë pritet të ndodhë në studim, dhe pohon ekzistencën e një marrëdhënieje midis variablave të studimit dhe drejtimin specifik të marrëdhënies.

Hipotezat burojnë nga supozimet ose nga frymëzimet, por pasi të jenë formuluar ato duhet të testohen në mënyrë të rreptë (pilotohen), duke përdorë metodën e duhur.

Në varësi prej problemit hulumtues, dhe asaj që dëshirojmë të nxjerrim me anë të hulumtimit, paraprakisht edhe parashtrojmë hipotezën.

Shembull:

1. Nëse tema është: Ndikimi i dhunës ndaj nxënësve në braktisjen e shkollës, dhe dëshirojmë të dimë se nxënësit e cilës gjini e braktisin më tepër shkollën si rezultat $i$ dhunës në shkollë, atëherë hipoteza alternative do të ishte: Dhuna e mësimdhënësve ndikon më shumë tek nxënësit e gjinisë femërore që ta braktisin shkollën, ose si hipotezë e përgjithshme mund të ishte: Dhuna ndaj nxënësve ndikon shumë që nxënësit ta braktisin shkollën.

2. Tema: Ndikimi i Mësimdhënies tradicionale dhe mësimdhënies ndërvepruese në procesin mësimor (krahasim) 
Hipoteza: Mësimdhënia ndërvepruese ndikon më mirë në procesin mësimor se sa mësimdhënia tradicionale.

\subsection{FORMULIMI I HIPOTEZAVE}

Hipoteza paraqet pikën fillestare në kërkim, që duhet të mbështetet në njohjen e thellë të problemit. Hipotezat duhet të jenë të formuluara qartë dhe thjeshtë, lidhur me supozimin e juaj për rezultatet e pritshme. Ajo përfaqëson bazën nismëtare për përcaktimin e qëllimeve dhe detyrave. (Azemi\&Bujari, 2013) Çdo kërkim eksperimentale ose shpjegues nis duke pritur ndonjë rezultat të caktuar. Kjo pritje e ndonjë rezultati është HIPOTEZA.

Hipoteza siguron nismë dhe nxitje për kërkim shkencor dhe ndikon në metodën e kërkimit.

Në dritë të kësaj pritjeje disa vrojtime vlerësohen si relevante dhe disa të tjera si jorevelvante, përdoret një metodologji ndërsa të tjerat jo, bëhen disa eksperimente dhe jo të tjera. Ku është kërkimi naiv, i pastër dhe objektiv këtu?!

Ekzistimi i principeve dhe rregullave metodologjike mbi mënyrën e formulimit të hipotezave është më se i domosdoshëm, jo për shkak se hulumtuesit do të zhvillonin një konceptualizim uniform të përgjigjeve të supozuara në problemet e parashtruara, por para së giithash, për shkak se principet dhe rregullat konsiderohen si domosdoshmëri. (Osmani, 2014)

Si bëhet pilotimi i hipotezës dhe si jemi në dijeni se ajo është e saktë? Nëse parashikimet dalin të sakta, atëherë hipoteza juaj është provuar (mbështetur) dhe mund të qëndrojë përderisa teste të ardhshme të provojnë josaktësinë e saj.

\subsection{MODIFIKIMI I HIPOTEZAVE}

Hipotezat mund të ndryshohen apo modifikohen në proces e sipër gjatë punës hulumtuese.

Nëse parashikimet e nxjerra nga hipoteza juaj nuk dalin të jenë të sakta, atëherë ju duhet të braktisni ose të modifikoni hipotezën.

Pasi të keni arritur tek hipoteza e juaj, që është produkt i imagjinatës tuaj, atëherë ju kaloni në një proces më rigoroz dhe logjik, bazuar në argument deduktiv-së këndejmi rrjedh termi 'hipotetiko-deduktiv'.

Kërkuesi gjithnjë duhet të formulojë një hipotezë para se ta testojë atë, për shembull, "Lëvdatat ndikojnë më shumë se qortimet në të nxënit e nxënësve të shkollës fillore".

Nuk ka shkencëtar që pret deri sa të mbledhë të githa të dhënat për të provuar t'u japë kuptim atyre.

Parashtrimi ngritja e hipotezave

Ngritja e hipotezave pas modifikimit mund të bëhet në tri forma:

Si shprehje eksplicite - kur nisemi nga fakti se ekziston korrelim midis dy variablave apo dukurive;

Së dyti si shprehje implicite - kur shtrojmë pyetje se a ekziston dallimi midis dy dukurive;

Se treti si shprehje zero - se nuk ekziston lidhja midis dy dukurive. 


\subsection{TESTIMI I HIPOTEZËS}

Hipoteza duhet të argumentohet në aspektin empirik dhe interpretimine arsyeshëm teorik në bazë të gjetjeve në kërkimet e mëparshme edhe nga analiza e literaturës për atë fushë. Të gjitha hipotezat e një studimi nuk duhet të bazohen vetëm në arsyetime ose në intuitë, por në radhë të parë duhet të formulohen dhe testohen mbi bazën e të dhënave që grumbullohen përmes vëzhgimit të dukurive të botës reale, ashtu siç ndodhin, ose përmes eksperimenteve (Azemi \& Bujari, 2013).

Hipoteza sprovuese është një hipotezë e mundshme, një parashtrim që duhet provuar, disaprovuar ose rishikuar. Pra, hipoteza duhet të 'provohet'. Megjithatë, ky është një term që, me disa përjashtime të vogla, nuk përdoret më në kërkimet bashkëkohore, sepse "provohet", por kjo varet nga konteksti vendor dhe rasti. P.sh. Ndikimi i rrethit shoqëror në edukimin e sjelljes.

Qëllimi i testimit të hipotezave është që të hidhen hipotezat jo të vërteta dhe të përkrahen hipotezat e vërteta.

Kur përcaktohet forma e distribuimit të testit statistikor mbi shkallën e vërtetësisë së hipotezës si dhe niveli i signifikancës, atëherë mund të përcaktohet edhe zona e pranimit të hipotezës zero. Nëse testi statistikor bie në zonën e pranimit, atëherë hipoteza zero konsiderohet si e saktë, ndërsa e refuzojmë hipotezën alternative. Në të kundërtën, kur vlera e testit statistikor bie në zonën e refuzimit të hipotezës, atëherë pranohet hipoteza alternative. (Osmani, 2014)

Po që se mesi aritmetik në një grup përfaqësues me lakore normale largohet nga mesi aritmetik i popullacionit më pak se 1.96 të devijimit standard, atëherë mund të përfundojmë me një gjasë prej $95 \%$ se hipoteza zero mbështetet, sepse dallimet janë shumë të vogla. (Bekteshi, 2005) Kur këto dallime janë më të mëdha se 1.96 gabime standarde, atëherë hipoteza zero nuk mbështetet nën shkallën $5 \%$ të sinjifikancës.

Testet statistikore të cilat zbatohen për të vërtetuar hipotezën, janë:

* Testet statistikore parametrike;

- Testi t;

- Testi ANOVA, etj.

* Testet statistikore joparametrike.

-Testi Hi katror $-\mathrm{X}^{2}$, etj.

a.Testi t.- është test parametrik, dhe zbatohet për testimin e hipotezës zero. Testi t, përdoret në të gjitha rastet kur duhet konstatuar nëse ekziston dallimi dhe sa është $\mathrm{i}$ rëndësishëm dallimi midis dy grupeve të mostrave për nga mesataret aritmetike. Testi $\mathrm{t}$, gjithmonë krahason dy mesatare apo dy vlera të ndryshme. Testi $t$, preferohet në rastet kur madhësia e mostrës nuk është e madhe, kur nuk dihet devijimi standard i popullimit që është marr nga mostra dhe kur parametrat e popullimit nuk përdoren në testin e hipotezës.(Kalayci, 2017)

b.Testi ANOVA.- është test parametrik, përdoret për vërtetimin e rëndësisë së diferencave ndërmjet më shumë mesatareve aritmetike. Në analizën dhe vërtetimin e efikasitetit të më shumë se dy faktorëve në kërkimet shkencore, zbatohet analiza e variancës,e cila zakonisht zbatohet për vërtetimin e hipotezës zero. 
c. Testi Hi katror $\mathrm{X}^{2}$.-është një test statistikor joparametrik, nëpërmjet të cilit maten marrëdhëniet ndërmjet variablave, kur ata janë nominalë dhe të numërueshëm, duke bërë të mundur që të numërohen frekuencat e çdo kategorie të variablave të matur, duke i lejuar studiuesve të testojnë pavarësinë e kategorive dhe të vlerësojnë efektin e tyre. Me anë të këtij testi, zakonisht verifikohen hipotezat zero. (Murati, 2004)

Për ta zbatuar procedurën e testimit të $\mathrm{X}^{2}$, duhet llogaritur frekuencat teorike dhe ato empirike, pastaj të gjenden dallimet në mes të këtyre frekuencave.

Testimi i hipotezës, mund të bëhet në mënyra të ndryshme dhe me anë të testeve të ndryshme, si ato parametrike dhe testeve joparametrike, mirëpo programet kompjuterike, ofrojnë mundësi të automatizuara për testimin e hipotezave. programi SPSS, është një program mjaftë i avancuar, e që ndihmon në analizimin e të dhënave të grumbulluara në terren, dhe ndër shumë operacione që mund të kryhen përmes këtij programi, është edhe testimi i hipotezave.

Më poshtë, me anë të tabelës dhe grafikonit, po e paraqesim testimine hipotezës përmes testimit joparametrik.

Tabela nr. 1. Testit Kolmogorov Smirnov

Hypothesis Test Summary

\begin{tabular}{|c|c|c|c|}
\hline & Null Hypothesis & Sig. & Decision \\
\hline 1 & $\begin{array}{l}\text { The distribution of Konfliktet në mes } \\
\text { të prindërure mund të ndikojnë në Qne-Sample } \\
\text { delikuencën e nxënësure të moshës Kolmogorov- } \\
\text { shkollore is nomal wuith mean } 4.53 \text { Smirnov Test } \\
\text { and standard deviation } 0.69 \text {. }\end{array}$ & .000 & $\begin{array}{l}\text { Reject the } \\
\text { nuil } \\
\text { hypothesis. }\end{array}$ \\
\hline
\end{tabular}

Asymptotic significances are displayed. The significance level is .05.

Grafikoni nr. 1. Testit Kolmogorov Smirnov

\section{One-Sample Kolmogorov-Smirnov Test}

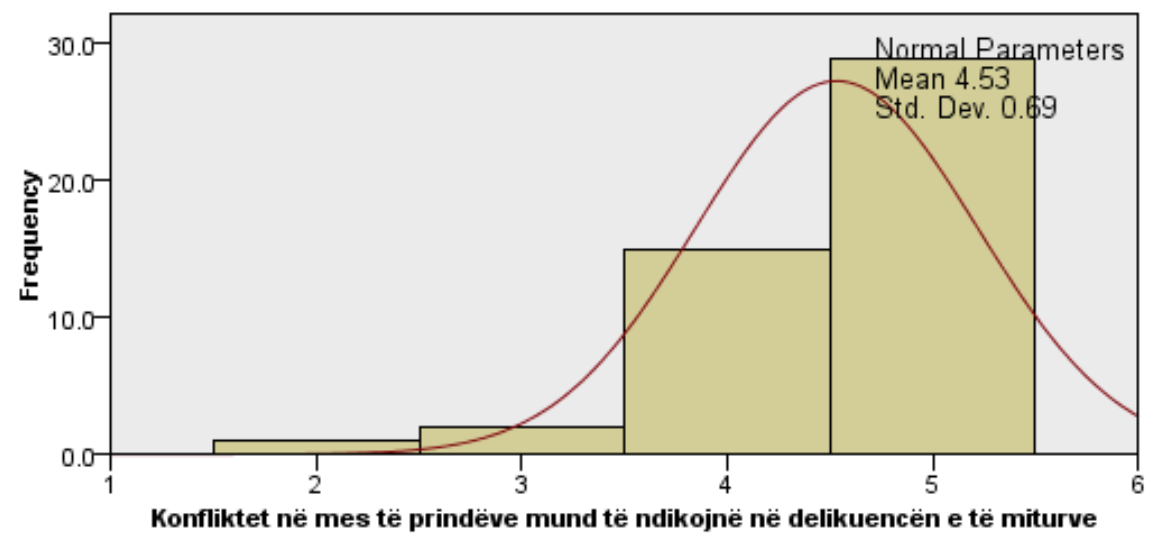


Me sa shihet në tabelën dhe grafikonin nr. 1, vërehet se mesatarja është 4.53, ndërsa devijimi standard është 0.69 , dhe në bazë të këtij rezultati, hipoteza zero nuk është mbështetur.

\subsubsection{GABIMET NË MARRJEN E VENDIMEVE}

Rreth hedhjes poshtë dhe pranimit të hipotezës shpeshherë bëhen dy lloj gabimesh. Këto gabime, në terminologjinë statistikore, janë të njohura si gabimi i tipit të parë ose alfa-a dhe gabime të tipit të dytë ose beta- $\beta$. Gabimi i tipit të parë na paraqitet kur përfundojmë se ka lidhshmëri ose dallime, e në të vërtetë nuk ka . ky tip i gabimit shfaqet kur hidhet poshtë hipoteza zero, edhe pese ajo është e vërtetë. (Bekteshi, 2005) Gabimi ndodh, sidomos kur e marrim nivelin $95 \%$ të gjasës, sepse zona e pranimit apo hedhjes poshtë të hipotezës është shumë e vogël, 1.96 gabime standarde.

Gabimi i tipit të dytë na paraqitet kur e përkrahim hipotezën zero edhe pse ajo është jo e vërtetë, kur përfundon se ka dallime, e në të vërtetë nuk ka dallime. Ky lloj gabimi shfaqet atëherë kur merret niveli $99 \%$ të mundësisë, kur zona e pranimit ose hedhjes së hipotezës zero është më e madhe se ai $95 \%$.

\subsubsection{NIVELI I RËNDËSISË (A) DHE INTERVALI I BESIMIT (1-A)}

Niveli i rëndësisë është një standard bazë statistikor për të refuzuar hipotezën zero. Në testimin e hipotezave, në të njëjtën kohë a tregon nivelin e rëndësisë. Qëllimi i nivelit të rëndësisë është që të japë një bazë rreth dallimeve të krijuara ndërmjet vlerës së mostrës dhe parametrave të popullimit që marrin pjesë në hipotezë dhe për të vendosur dallimet a janë krijuar rastësisht apo janë të rëndësishme në mënyrë statistikore.

Niveli i përzgjedhur i rëndësisë siguron përcaktimin e zonave të pranimit dhe të refuzimit në shpërndarjen e mostrës. Zakonisht përdoret niveli i rëndësisë prej 0.01 , 0.05 , por mund të përdoren edhe vlera më të mëdha si 0.10. (Kalayci, 2017)

Niveli i rëndësisë mund të shpjegohet edhe përmes konceptit të intervalit të besueshmërisë. Niveli i rëndësisë prej $5 \%$ shpreh intervalin e besueshmërisë prej 95 $\%$.

Në bazë të dy llojeve të gabimeve, ekzistojnë edhe dy lloje të vendimeve të sakta: pranimi i hipotezës së saktë zero dhe refuzimi i hipotezës së gabuar zero. Në qoftë se niveli i rëndësisë është 0.05 , probabiliteti i pranimit të një hipoteze të saktë zero është $1.00-\mathrm{a}=1.00-0.05=0.95$.

\subsection{FUNKSIONI I HIPOTEZAVE}

Hipoteza e kërkimit ka dy funksione themelore:

Përcakton qëllimin e kërkimit;

Përcakton mënyrat e kërkimit (metodat teknikat, instrumentet dhe llojin e të dhënave) për ta verifikuar ose hedhur poshtë. 
Hipoteza parqet një "orientim" ide udhëheqëse në rrugën e kërkimit, e cila na shërben edhe në seleksionimin e fakteve për verifikimin e saj.

Andaj ne literaturë flitet për tri funksionet kryesore të hipotezës që janë:

- konstatimi dhe shpjegimi i fakteve;

- shpjegimi i lidhjes konkrete midis gjësendeve;

- shpjegimi i lidhjeve midis atyre proceseve që janë thelbësore dhe atyre që nuk janë thelbësore.

Nga hipoteza varet qasja, përcaktimi i metodave, teknikave, instrumenteve dhe zbatimi i procedurave hulumtuese.

\subsection{VLEFSHMËRIA E HIPOTEZËS NË KËRKIM}

Një hipotezë shkencore është me vlerë më të madhe njohëse, me shumë gjasa të verifikohet nëse është valide.

Për të qenë valide ajo duhet të ketë:

- Mbështetje në sa më shumë fakte të mbledhura paraprakisht dhe me plan;

- Të jetë rrjedhojë nga njohuritë e mëparshme të kërkuesit;

- Që ka lidhje të drejtpërdrejt me temën që hulumtohet;

- E Eshtë e frytshme, d.m.th nëse me anë të saj mund të shpjegohen sa më shumë dukuri, apo procese që hulumtohen;

- Të jetë sa më e thjesht domethënia, nëse asaj nuk i nevojiten hipoteza të tjera ndihmëse.

- Kur hipoteza është e vlefshme pas testimit dhe e formuluar mirë, atëherë hipoteza ngrihet në nivel të tezës (gjeneralizohet) dhe ju do të jeni në gjendje të gjykoni mbi bazën e saj. 


\section{BIBLIOGRAFIJA}

1. Azemi, Bashkim \& Remzi Bujari. 2013. Bazat e kërkimit në edukim, Instituti Pedagogjik i Kosovës, Prishtinë.

2. Bektteshi, Bektesh. 2005. Statistika elementare, "Libri shkollor", Prishtinë.

3. Cohen, L. \&L.,Manion. 1990. Research Methods in Education. London: Routledge.

4. Dadds, M. 2002. "Taking Curiosity Seriously: the role of awe and Wanda in researchbased professionalism", Educational Action Research, 10.

5. Kalayci, Șeref (redaktor). 2017. Teknikat statistikore me shumë ndryshore me aplikim në SPSS (përktheu Nga botimi i 6, Kujtim Hameli). https://www.scribd.com/.../Teknikat-Statistikore-Me-Shume-Ndryshore-MeAplikim-Ne-...

6. Karaj, Th., E., Rapti. 2001. Kërkimi shkencor në shkencat e edukimit, AEDP, Tiranë.

7. Kemmis, Stephen, and McTaggart, Robin, eds. (1988). The action research planner third edition. Victoria: Deakin University.

8. Kocani, Aleksandër. 2008. Udhëzuespërpërdorimin e paketës statistikore për shkencat sociale (SPSS), Tiranë.

9. Matthews, Bob dhe L., Ross. 2010. Metodat e hulumtimit (udhëzues praktik për shkencat sociale dhe humane), CDE, Tiranë.

10. Murati, Xh. 2004. Metodologjia e kërkimit pedagogjik (botimi i tretë i plotësuar), "Qabej", Tetovë.

11. Publication Manual of the American Psychological Association. 2002. fifth edition, Washington DC.

12. Osmani, Qufli. 2014. Metodologjia e hulumtimit shkencor në psikologji (botimi iparë), Tetovë.

13. Wellington, J., 2000, Educational Research: contemporary issues and practical approaches, London: Continuum

14. Wilson, E. (ed) (2009) School-based research; a guide for education students. Sage Publications

\section{RESUME}

There are various aspects that you manage in a class that can be directed (to students as an individual, to a student group and to a department as a social unit, to a teacher and his styles of leadership and management in the classroom, on techniques and procedures for creating and maintaining discipline). However, there are some general points to be considered, regardless of what their attention is focused on, which is reflected in the endeavor of influencing self-discipline as the ultimate goal of the teaching process.

Meta analysis, as well as video studies and studies that have increased learning effects, provide the answer: In any case, effective classroom management is required, which implies the complexity of group events so that it is reduced, and all learning and learning stakeholders are loaded with a small number of errors . behavior. In doing so, it is not a problem in "understanding" the dimension of teaching and learning, but 
in their realization and synchronization in teaching. Overall, research shows that relatively more rigorous and disciplined teaching is more convenient for achieving cognitive and social success in teaching, and teachers are required to become a reflex practitioner who rejects the attitude and behavior of researchers, who assesses, the effects and impacts of their work, opportunities to improve and Professionalization and saving is to cut off its routine knowledge structures. Reflexive practical work professionally, explores and examines his own beliefs and perceptions about the possibilities of action, trying to modify them in order to pass his own field. When asked if you pass the techniques correspond to his beliefs and values, as well as to a specific group of students in a specific situation. In solving the problem, it connects its strategies to the current situation and needs of students, all through the ability to generate new, better organize behaviors. He is a researcher in the social system of the group who teaches and at the same time experimenter in the laboratory of the classroom. 